\title{
Leaders
}

\section{Protein kinase C: a family of isoenzymes with distinct roles in pathogenesis}

\author{
J M Lord, J Pongracz
}

\section{Background}

There is no doubt that the advances made in the field of molecular biology in the past two decades have greatly increased our understanding of the genetic and molecular basis of disease. Despite this progress, the immediate impact of genetics on the treatment of disease is still some way off. Cancer mortality in the Western hemisphere, where reliable statistics are available, has shown no significant decline in the past 45 years. ${ }^{1}$ Gene therapy is an unlikely treatment for diseases such as cancer, which have a significant non-genetic component ${ }^{2}$; the range of diseases that are realistically amenable to approaches such as gene therapy are limited. Thus, the search for new therapeutic modalities is more frequently targeted towards intracellular events, particularly the intracellular signalling pathways, which regulate cell function and will frequently involve alterations in gene expression. Although the fine details of specific signalling pathways are complex, the principles involved in transducing a signal from the plasma membrane into a biological effect are remarkably similar (fig 1). The way forward for the treatment of many diseases may well lie in the modulation of one or more elements in these signalling pathways. Whilst our know-
Department of Immunology, Birmingham University Medical School,

Birmingham B15 2TT J M Lord

J Pongracz

Correspondence to: Dr J M Lord.

Accepted for publication 2 February 1995

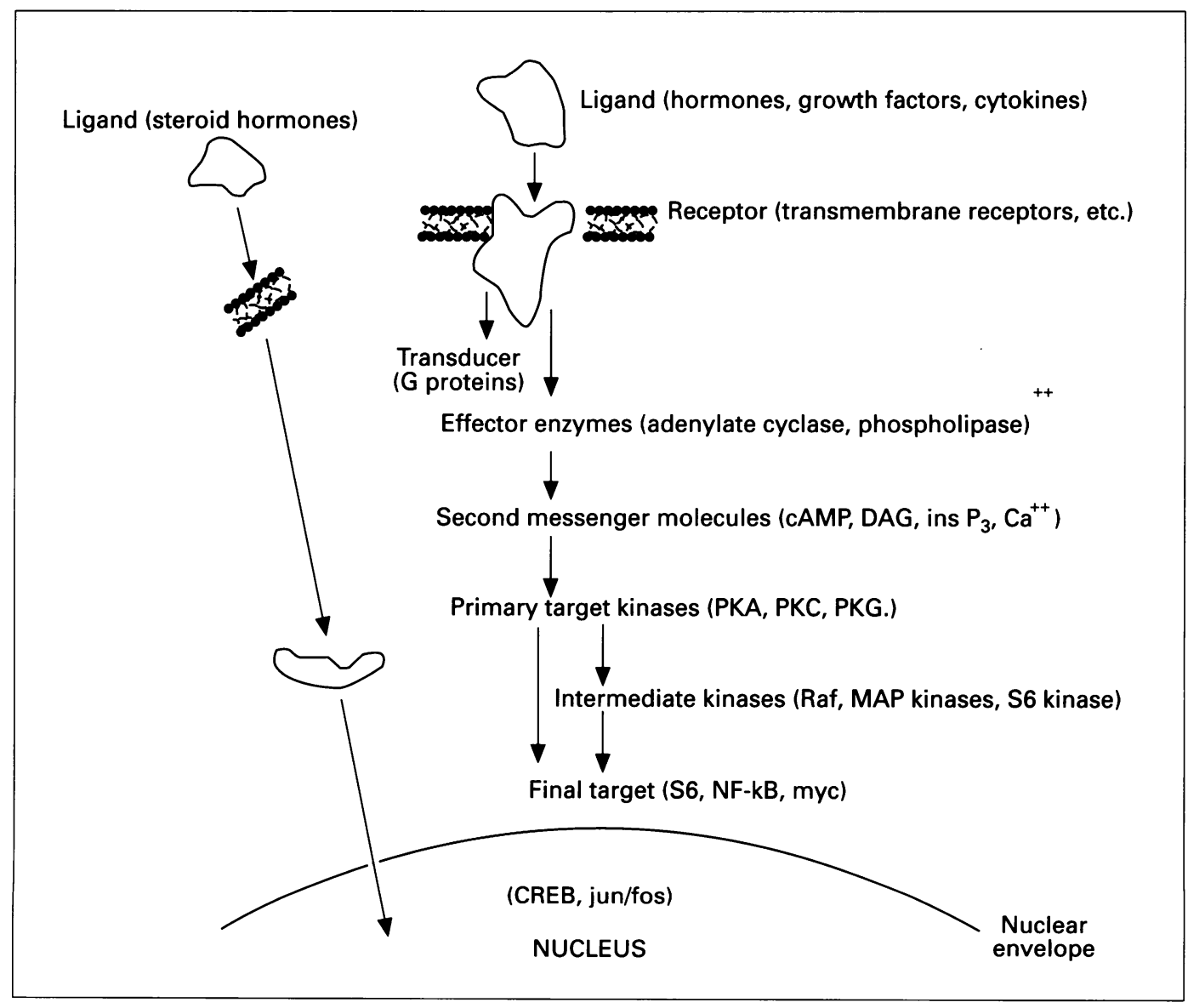

Figure 1 Intracellular signalling pathways-a simplified scheme. Cells are regulated by a variety of external ligands, which mediate their effects via binding to specific receptors. With the exception of steroid hormones, the receptors are located on the plasma membrane and intracellular events are modified as a result of $a$ signalling cascade initiated at the plasma membrane. The earliest elements in the cascade are tyrosine kinases or transducer proteins which activate a variety of enzymes, generating second messengers. The second messengers then activate a range of protein kinases which can directly modify cellular proteins or modulate gene expression by activation of a further series of kinases. 
ledge of the structure and function of individual signalling elements, and their interplay, is incomplete, it should ensure that the most appropriate targets are selected for drug intervention.

In recent years we have seen an explosive growth in our understanding of the complexity of signals received by cells. These signals consist of soluble factors and membrane bound ligands on adjacent cells, which together regulate the cells' response to the environment. The intracellular signalling pathways elicited by receptor-ligand interactions frequently comprise enzyme cascades, the complexity of which is further increased by cross-talk between elements of these pathways. The major challenge for the future will be to understand how these signalling pathways interact to regulate normal physiology and how their disregulation contributes to disease. One signalling element that has been extensively studied and implicated in a wide variety of diseases is the serine/threonine kinase, protein kinase C (PKC). PKC was first described by Nishizuka as a calcium and phospholipid dependent protein kinase, which also required diacylglycerol (DAG) for full enzyme activity. ${ }^{3}$ A pivotal role for PKC in the regulation of cell proliferation and differentiation was soon recognised, based initially on data showing that many growth and differentiation factors mediated their effects via the stimulation of phosphatidylinositol (PI) turnover. PI breakdown generates DAG and increases intracellular $\mathrm{Ca}^{++}$concentrations, via production of inositol trisphosphate, ${ }^{4}$ thus providing the co-factors for PKC activation. The identification of PKC as the major intracellular receptor for the tumour promoting phorbol esters $^{5}$ has further implicated PKC in the modulation of cell proliferation.

As the interest in PKC has increased, the perception of its involvement in cell regulation has been extended beyond cell proliferation. It is now clear that PKC is involved in signalling pathways mediating the regulation of many basic cell processes including cell-cell interactions, ${ }^{6}$ secretion, ${ }^{78}$ cytoskeletal function, ${ }^{910}$ gene expression, ${ }^{1112}$ cell differentiation, ${ }^{13}$ and cell survival. ${ }^{1415}$ Such a broad spectrum of involvement for PKC initially presents problems regarding specificity in cell signalling. If a wide range of receptors are linked to PKC, how is the specificity of their biological effects maintained? The discovery of isoenzymes of PKC, by cloning complementary DNAs (cDNAs) mainly from brain cDNA libraries ${ }^{1617}$ has helped to resolve this problem. Thus, PKC is not a single entity, but a family of related isoenzymes.

Twelve mammalian PKC isoenzymes have been described to date ${ }^{18}$ and the list will most likely increase over the next few years. The isoenzymes of PKC have different requirements for co-factors and show differential tissue distribution and substrate specificities. As the individual PKC isoenzymes also show a high degree of conservation across mammalian species, ${ }^{18}$ they are likely to have specific functions within cells. Moreover, the modulation of PKC isoenzyme expression, subcellular location and substrate availability give the potential for further specificity in PKC mediated cell signalling.

\section{PKC isoenzymes: heterogeneity of} structure and function

Several comprehensive reviews of PKC isoenzyme structure and function have been published recently ${ }^{18-20}$ and will not be repeated here extensively. However, whilst this article is primarily concerned with the role of PKC isoenzymes in disease pathogenesis, a brief summary of our current understanding of the biochemistry of PKC isoenzymes, in particular their distinct activation and regulation, is still required. Relevant reviews, rather than specific original papers, have been quoted in each area.

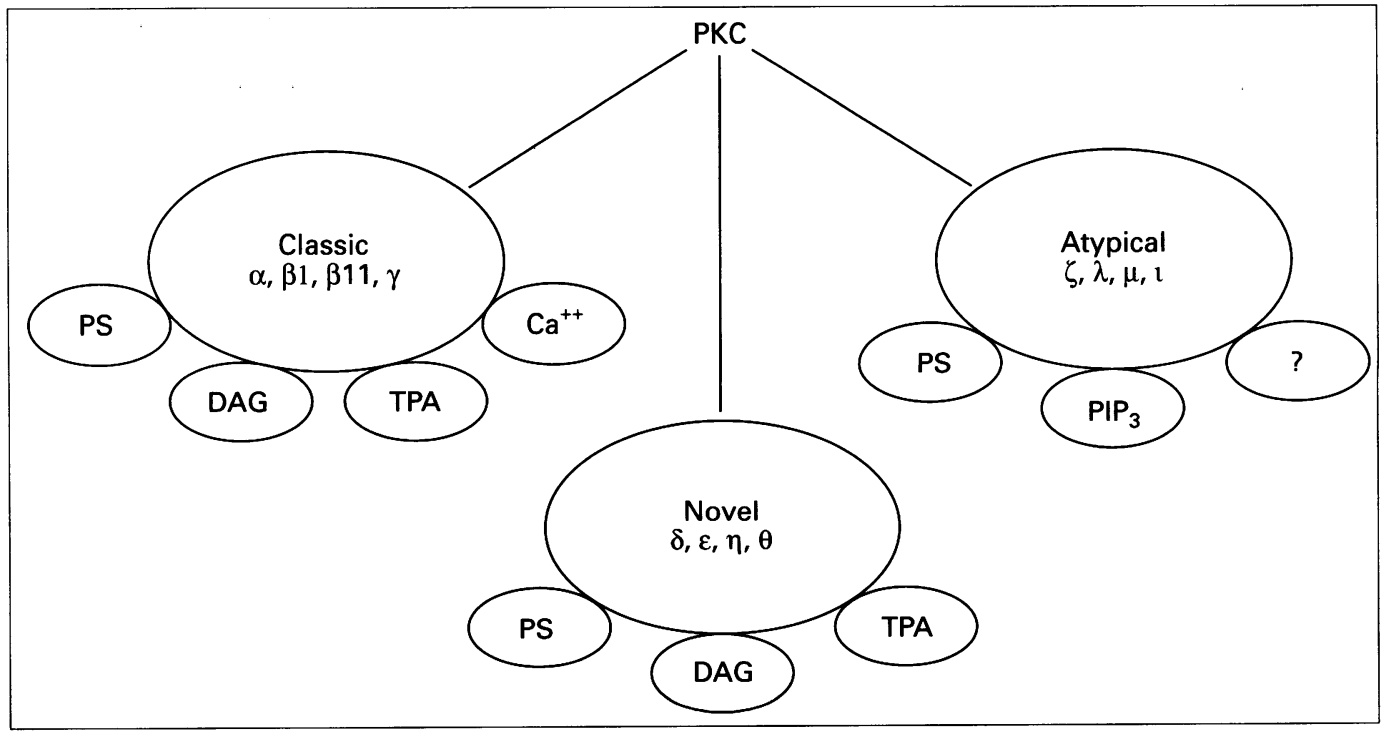

Figure 2. The PKC family of isoenzymes currently consists of 12 isoenzymes which can be subdivided into three groups, the classic, novel and atypical $P K C$. The groups differ in their requirement for $\mathrm{Ca}^{++}$and their ability to be activated by various lipid species, including DAG. All of the isoenzymes require phosphatidylserine for full enzyme activity. 
STRUCTURE

From biochemical studies and cDNA cloning, it has been revealed that PKC represents a family of closely related isoenzymes (fig 2). These isoenzymes can be divided into three main groups: the $\mathrm{Ca}^{++}$dependent, phorbol ester binding, classic c-PKCs $(\alpha, \beta I, \beta I I, \gamma)$, the $\mathrm{Ca}^{++}$independent, phorbol ester binding, novel n-PKCs $(\delta, \varepsilon, \eta, \theta)$ and the $\mathrm{Ca}^{++}$independent, non-phorbol ester binding, atypical a-PKCs $(\zeta, \lambda, \mu, \imath) .{ }^{18}$ The structure of PKC isoenzymes has been reviewed in depth recently. ${ }^{1920}$ Briefly, all of the PKC isoenzymes possess a catalytic and a regulatory subunit which are separated by a proteolysis sensitive hinge region. The $\mathrm{C}$ terminus in all PKC isoenzymes contains the catalytic domain and the ATP and substrate binding sites. The $\mathrm{N}$ terminus contains the regulatory domain, where the c-PKCs have a $\mathrm{Ca}^{++}$binding site and cPKCs and n-PKCs have a cysteine-rich region necessary for DAG and phorbol ester binding. These latter domains are absent from the regulatory domain of a-PKCs and the factors activating this group of PKCs are still unknown, though phosphatidyl $(3,4,5)$-inositol trisphosphate $\left(\mathrm{PIP}_{3}\right)$ has been implicated by two separate laboratories. ${ }^{2122}$ At the start of the regulatory domain, a sequence motif has been found which is similar to the consensus sequence found in PKC substrates. However, the serine or threonine residue found in the substrate motif is changed to alanine and this motif represents a pseudosubstrate site that blocks the catalytic (substrate binding) site in unactivated PKCs. The binding of DAG and other lipid activators is thought to induce a conformational change and remove the inhibition imposed by the pseudosubstrate site. Activation also reveals the proteolysis sensitive site and PKC is cleaved by calpain to a cofactor independent form, PKM.

\section{ACTIVATION}

The activation processes of c-PKCs are relatively well studied but less is known regarding n-PKCs and a-PKCs. For c-PKCs, the binding of $\mathrm{CA}^{++}$to the catalytic domain results in the translocation of PKC from the cytosol to the membrane fraction. PKC can then bind DAG and phosphatidylserine (PS) to achieve full enzyme activation. n-PKCs do not require $\mathrm{CA}^{++}$for activation but they do require DAG and PS. The factors which mediate their translocation to cell membranes are unknown. a-PKCs do not appear to require DAG for activation, but PKC $\zeta$ activity is stimulated by PS or unsaturated fatty acids-for example, arachidonic acid. As mentioned above, $\mathrm{PIP}_{3}$ is also able to activate this PKC isoenzyme and PKC $\zeta$ has therefore been implicated in signalling pathways mediated by $\mathrm{PI}_{3}$ kinase..$^{2122}$ As the generation of DAG from $\mathrm{PIP}_{2}$ is transient, other lipid co-factors have also been proposed as mediators of PKC activation. These include DAG from other membrane lipids, as well as other products of lipid hydrolysis. ${ }^{20}$ The PKC family all depend on PS, but respond differently to these phospholipid metabolites-for example, PKC $\eta$ is most effectively activated by cholesterol sulphate ${ }^{23}$ and PKCs are differentially responsive to lysophosphatidic acid. ${ }^{24}$ PKC can also be inhibited by certain lipids, notably the products of sphingolipid hydrolysis, but nothing is known of isoenzyme susceptibility to these molecules.

In recent years it has become evident that protein kinases, including PKC, exhibit a pronounced autophosphorylation which is often linked to kinase activation. Detailed studies have revealed that autophosphorylation occurs at serine and threonine residues on both the regulatory and catalytic domains of PKC. Moreover, the various PKC isoenzymes show certain differences in their autophosphorylation sites. ${ }^{20}$ PKC $\beta$ II phosphorylates on both serine and threonine residues, PKC $\alpha$ and $\zeta$ exclusively autophosphorylate on serine, while PKC $\beta I$ autophosphorylates primarily on threonine residues.

\section{DOWNREGULATION}

When activated PKCs are translocated to the plasma membrane, they can be proteolysed by the neutral proteases calpains I and II. Calpains cleave PKC in the hinge region and thus produce two distinct fragments: a protein comprising the regulatory domain and a protein containing the kinase domain, which is catalytically active in the absence of any activators. The latter fragment is termed PKM. In several different cell types prolonged treatment with phorbol esters results in depletion of cellular PKC. This is because phorbol esters cannot be metabolised within cells and they produce continuous activation of PKC, which ultimately leads to its proteolysis and downregulation. Whether PKC downregulation is as extensive with physiological activators of PKC remains to be determined. The various PKC isoenzymes exhibit quite extreme differences in their susceptibility to downregulation. Some are relatively resistent to calpain and trypsin mediated downregulation-for example, PKC $\alpha,{ }^{25}$ whilst others are more easily inactivated by proteolysis-for example PKC $\beta$ and $\gamma .^{25}$

Further work is necessary to determine the role of proteolytic cleavage in PKC activation, degradation, relocation to cellular compartments, and determination of substrate specificity.

\section{SUBSTRATE SPECIFICITY}

PKC isoenzymes show great variations in their substrate specificity-for example, c-PKCs are very active towards histone IIIS and protamine, whereas n-PKCs or a-PKCs exhibit a very poor kinase activity towards these substrates. Dekker and Parker have recently reviewed the substrate specificity of PKC isoenzymes ${ }^{18}$ and many examples of differential protein phosphorylation by PKC isoenzymes have now been reported. Clearly, this aspect of PKC isoenzyme biochemistry will greatly influence their regulation of biological effects. The cellular PKC substrates include proteins involved in most cell functions, including other proteins involved in 
$P K C$ and PKC isoenzymes in disease

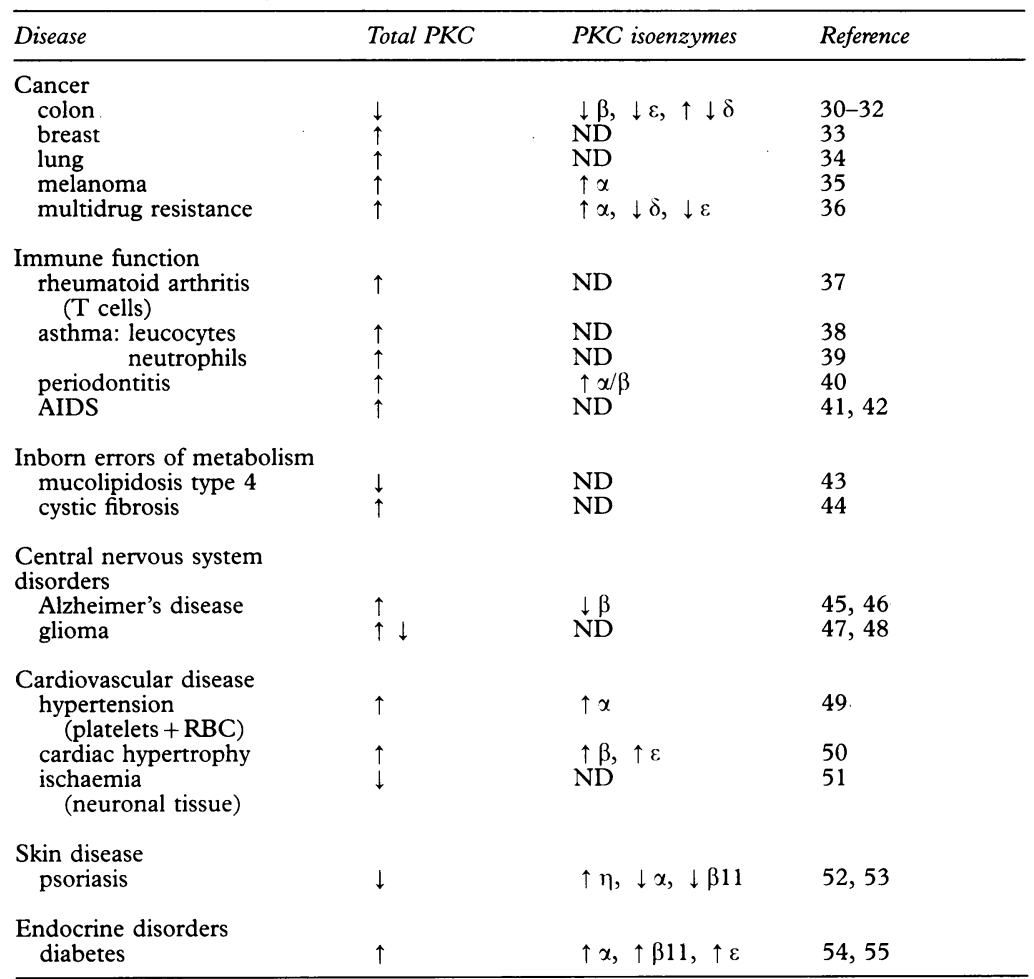

$\mathrm{RBC}=$ red blood cells.

Note: Total PKC activity or expression has been measured in a wide range of diseases and values for disease tissue compared with normal ( $\uparrow$ or $\downarrow$ ). In some studies the expression of individua PKC isoenzymes was also assessed and those isoenzymes that were altered in disease are shown

signal transduction (for example, phospholipase C, Raf), proteins involved in metabolism and proteins involved in gene expression and the control of DNA synthesis (transcription factors, DNA topoisomerase I and lamin B). Again, a full review of the known substrates of PKC is not relevant to this leader and only a brief mention of the range of PKC substrates needs to be given to realise its potential involvement in cell function.

TISSUE AND CELLULAR DISTRIBUTION OF PKC ISOENZYMES

The 12 known PKC isoenzymes appear to be selectively distributed among different tissues, indicating their specialised role in certain tissue functions. There may be a distinction between isoenzymes for general housekeeping functions in cells and those for distinct functions in differentiated and specialised cells. ${ }^{20}$ Certain PKC isoenzymes appear to be universally present in all human cells; these are PKC $\alpha, \delta$ and $\zeta$. In contrast; PKC $\gamma$ is found exclusively in the central nervous system, PKC $\eta$ is strongly expressed in skin and lung, PKC $\theta$ predominates in skeletal muscle cells, and PKC $\lambda$ is found mainly in ovary and testis.

The intracellular distribution of PKC isoenzymes is almost as varied as their tissue distribution. PKC $\alpha$ is found mainly in the cytosolic fraction and after activation, translocates to the plasma membrane and very often to the nuclear membrane. PKC $\delta$ is often associated with the particulate cell fraction and has been shown to associate with the cytoskeleton upon activation. ${ }^{9}$ In myocytes PKC $\delta$ is specifically located in the nucleus from where it translocates to the perinuclear region during activation. ${ }^{10}$ Similar findings have been reported for PKC $\beta$. It has been shown that PKC $\beta$ associates with vimentin-type intermediate filaments ${ }^{26}$ and during activation it translocates to the perinuclear region. PKC $\zeta$ is located in the cytosol in most cells and has been shown to translocate to the perinuclear region following activation. Thus, specificity in PKC function is generated at the level of activation by co-factors, downregulation following activation, subcellular location, and substrate specificity. All of this will, in turn, affect the role of PKC isoenzymes in disease.

\section{PKC and disease}

As the PKC pathway is involved in the regulation of cell proliferation, and cell proliferation is an important contributor to neoplastic disease, a role for PKC in malignancy has been proposed by several authors. ${ }^{27-29}$ Altered expression of PKC has been reported in a very wide range of neoplastic and pre-neoplastic tissues (table) and more recently, PKC has also been implicated in cancer metastasis. ${ }^{56}$ Moreover, we now know that the regulation of cell numbers is not merely a function of the rate of cell proliferation; the rate at which cells enter cell death or apoptosis is also a major factor in neoplasia. ${ }^{57} \mathrm{Ac}-$ cordingly, PKC has now been identified as a regulator of cell survival, with the tumour promoting effects of phorbol esters ascribed in part to their inhibition of apoptosis. The potential for therapeutic modulation of PKC in the treatment of cancer has been recognised for several years ${ }^{589}$ and at least one agent that modulates PKC, bryostatin 1 , is currently in phase 1 clinical trials as an anticancer drug. However, the consideration of such agents should not be restricted to their potential as anticancer drugs. ${ }^{59}$

As appreciation of the pleiotropic involvement of PKC in the regulation of cell functions has increased, its perturbation in disease states other than cancer has been proposed. The plethora of diseases that are now known to be associated with alterations in PKC activity or expression (table) may simply reflect its involvement in the regulation of many basic cell functions. For instance, the importance of PKC in cell differentiation ${ }^{13}$ is suggested by studies of PKC activity in malignant tissue, in which differentiation is disregulated. Similarly, its expression is also altered in psoriasis, a disease characterised by hyperproliferation and accelerated differentiation of epidermal keratinocytes. ${ }^{60}$ In addition, cytoskeletal elements, including several keratinisation related proteins, are known to be PKC substrates, ${ }^{6162}$ further implicating PKC in disorders of epidermal differentiation. Involvement of PKC in diseases reflecting altered gene expression has also been reported. Chemotherapy associated multidrug resistance is a multifactorial condition, with a prime factor being the expression of MDR genes. The expression of one gene, $M D R 1$, has been correlated with increased PKC activity in multidrug resistant MCF-7 
breast carcinoma cells. ${ }^{36}$ Sensitivity to chemotherapeutic agents was restored by treatment of these cells with the PKC inhibitor staurosporine. Furthermore, PKC has been shown to play a role in the pathogenesis of several inborn errors of metabolism. In cystic fibrosis, a disorder of electrolyte transport, the cystic fibrosis gene product is a transmembrane conductance regulator. The efflux of $\mathrm{Cl}^{-}$is defective and is potentiated by PKC. ${ }^{44} \mathrm{~A}$ second genetic disorder, type 4 mucolipidosis, also involves PKC but in this disease PKC activity is severely reduced due to inhibition by sphingolipids. Thus, altered PKC is not the primary cause of this disease, but its modulation by metabolites raised in this disorder may be the pathogenic mechanism. ${ }^{43}$ The role of PKC in secretion is of relevance to several diseases, including diabetes ${ }^{555}$ and inflammatory conditions such as rheumatoid arthritis ${ }^{37}$ and septic shock. Tumour necrosis factor (TNF) is thought to be the main inflammatory agonist responsible for inducing septic shock and PKC activation is required for the lipopolysaccharide (LPS) stimulated release of TNF from Kupffer cells. ${ }^{7}$ Finally, the regulation of membrane protein expression and therefore surface cell phenotype is also a process which involves PKC. ${ }^{6}$ Consequently, cell-cell communication and contact are partially regulated by PKC. One important consequence of this involvement is the regulation of homotypic and heterotypic cell adhesion. The disruption of these processes would have severe implications for many physiological functions including immune surveillance and cell survival within tissues. Disregulation of cell-cell contacts is one primary factor in tumour cell metastasis ${ }^{63}$ and the involvement of PKC has recently been suggested from studies of the antimetastatic ability of PKC inhibitors. It is probable that the full extent of PKC involvement in pathogenesis has not yet been revealed and only a sample of the vast literature on this subject can be presented in this review. The major diseases that show involvement of PKC are therefore indicated in the table. However, what is likely to be more germane to understanding the precise role of PKC in pathogenesis, and to the rational design of new therapeutic agents, is the identification of the specific isoenzymes of PKC involved in particular disease states.

\section{PKC isoenzymes and disease}

As seen in the table, data concerning PKC isoenzymes and disease are still lacking in many cases. Where isoenzyme data are available they are usually based upon a single report or are contradictory, reflecting a need for further precise studies in this area of research. Studies that have simply invoked a role for PKC in a particular disease, including many of those recorded in the table, have involved the measurement of total PKC activity in normal and diseased tissue. This may then have been followed by experiments showing that the disease state could be induced by agents that are known to activate PKC, usually the phorbol ester TPA; or alternatively that the disease phenotype could be abrogated in disease models by broad range PKC inhibitors, such as $\mathrm{H} 7$ or staurosporine. ${ }^{6465}$ To date, the use of such broad range PKC activators or inhibitors for the treatment of disease in humans has been very limited. As stated earlier, phase 1 clinical trials are currently in progress, assessing the anticancer potential of an activator of PKC, bryostatin 1 . Yet the potential for regulation of PKC as a therapeutic tool in a wide range of diseases is clearly indicated ${ }^{58963}$ Undoubtedly, the present lack of information regarding the precise functions of the PKC isoenzymes, a paucity of agents able to selectively modulate the isoenzymes and concern about widespread and non-specific side effects, have led to caution in the therapeutic use of PKC regulating drugs.

Progress is now being made towards the identification of agents that can selectively activate PKC isoenzymes. Several compounds show selectivity in their ability to activate PKC isoenzymes in vitro, including phorbol ester derivatives, ${ }^{66}$ bile acids ${ }^{30}$ and a marine polyether compound, Bistratene A. ${ }^{6768}$ Caution is required in the use of these agents, as there is evidence that the specificity of certain of these compounds is not retained in vivo. ${ }^{69}$ Examples are now also emerging of agents that show selectivity in their inhibition of PKC isoenzymes. The staurosporine analogs Ro318425 and Ro318220 are more effective towards the c-PKCs ${ }^{70}$ and the compound 13-hydroxy-7octadecadienoic acid inhibits PKC $\beta .^{71}$ It is still too early to predict the impact of these drugs on disease therapy, but their efficacy can only be realised if the isoenzymes primarily influencing specific disease phenotypes are identified.

The availability of PKC isoenzyme specific antisera and full length nucleotide sequences for the isoenzymes has meant that both immunological and molecular biology approaches can now be used to investigate PKC isoenzymes in disease. Both the level of expression of PKC isoenzymes and their activation state can be determined; the latter by assessing either the proportion of PKC associated with cell membranes/cytoskeleton or by measuring the autophosphorylation of individual PKC isoenzymes. Both are correlates of PKC activation. As shown in the table, progress is being made towards identifying which isoenzymes are altered in disease and in several cases the new data have allowed the authors to propose new pathogenic mechanisms. ${ }^{304355}$ As it is beyond the scope of this review to discuss the role of specific PKC isoenzymes in all of the diseases listed in the table, we will restrict this final section to a consideration of PKC isoenzymes in neoplasia. The identification of specific PKC isoenzyme involvement in disease is most extensive for cancer, has increased understanding of neoplastic progression and has begun to influence the design of novel anticancer drugs. ${ }^{5859}$

Studies of colorectal cancer have shown that carcinogenesis is a multistep process, with distinct stages of initiation and progression. The various genetic aberrations underlying these stages are now well characterised. ${ }^{72}$ Dogma has 
for a long time held that cancer was a disease of hyperproliferation and that the DNA mutations detected in colorectal cancer revealed genes involved in cell growth. It is now clear that apoptosis is an equally important regulator of cell numbers and aberrations of p53, a gene with a key role in the regulation of apoptosis, ${ }^{73}$ are among the most common mutations detected in human tumours. ${ }^{57}$ The modulation of genes involved in apoptosis, or their gene products and targets, offers a new direction for cancer therapy ${ }^{57}$; however, this should not be pursued to the exclusion of other possibilities. As mentioned at the beginning of this article, cancers such as colorectal cancer have a significant non-genetic component involved in disease progression. PKC is the cellular target for several tumour promoters and therefore its role lies in the promotion of neoplasia rather than its initiation. As such, PKC could clearly be involved in the regulation of proliferation and apoptosis. Furthermore, published data indicate that only certain PKC isoenzymes are involved in regulating these processes. ${ }^{1315}$

The initial use of TPA as an activator of PKC has led to much confusion over the role of PKC in cell proliferation and apoptosis. In some cell lines TPA was shown to be cytostatic, ${ }^{7475}$ whereas in others it was mitogenic. ${ }^{7677}$ TPA has been reported to prevent apoptosis induced by a variety of factors, ${ }^{1478}$ whilst other authors showed that TPA induces apoptosis. ${ }^{7980}$ TPA activates PKC isoenzymes differentially, having no effect on the a-PKCs. In addition, TPA can differentially downregulate PKC isoenzymes. In rat pituitary cells treated with TPA, Kiley has shown that PKC $\beta$ and PKC $\varepsilon$ were completely downregulated, whereas PKC $\alpha$ was only partially reduced. ${ }^{81}$ When this is taken into account with the differential tissue expression of PKC isoenzymes, it is not surprising that conflicting data were gained by different laboratories. The conflict is now being resolved and it is becoming clear that certain PKC isoenzymes are frequently associated with proliferation and apoptosis, whilst others are involved in differentiation. In myeloid and erythroid progenitor cells, PKC $\alpha$ and $\delta$ appear to be crucial for cell differentiation, ${ }^{8283}$ whereas PKC $\beta$ is involved in proliferation. ${ }^{8384}$ As cell proliferation and cell death are intimately linked ${ }^{85}$ it is perhaps not surprising that several laboratories, including our own, have reported the involvement of PKC $\beta$ in apoptosis. ${ }^{15887}$ The molecular basis for an involvement of PKC $\alpha$ and $\delta$ in differentiation is not known, but PKC $\beta 11$ has recently been shown to be a mitotic lamin kinase. ${ }^{84}$ Goss $e t ~ a l^{84}$ have shown that PKC $\beta 11$ is one of the kinases involved in the phosphorylation of nuclear lamin $B$ before lamina disassembly and mitosis. Exactly how this isoenzyme could also be involved in apoptosis has yet to be demonstrated. However, the onset of apoptosis is also known to require the disassembly of the nuclear lamina. ${ }^{88}$ One possibility is that in proliferating cells the activity/expression of PKC $\beta 11$ is closely regulated throughout the cell cycle, along with the other mitotic lamin kinases. It may be that prolonged or inappropriate activation of PKC $\beta 11$ produces prolonged lamina disassembly and aberrant mitosis, leading to apoptosis. Whilst this hypothesis is likely to represent an oversimplified version of the apoptotic process, there are some supporting data. The deoxyphorbol ester 12-deoxyphorbol-13-phenylacetate-20-acetate (Doppa) is specific for the activation of PKC $\beta$ in vitro ${ }^{66}$ and induces apoptosis in promyeloid cell lines. ${ }^{86}$ As the in vivo specificity of this agent has been questioned, ${ }^{69}$ these data must be taken as preliminary evidence only. However, expression of PKC $\beta$ is also increased as neutrophils become senescent and enter apoptosis ${ }^{89}$ and PKC $\beta$ expression also correlates with apoptosis in tonsil epithelial cells. ${ }^{87}$ Thus, although the involvement of PKC $\beta$ in proliferation and apoptosis is suggested by several lines of evidence, the interplay between these two functions is still unknown. However, this isoenzyme clearly represents a possible target for future therapeutic regimes. Whether this is the only isoenzyme with this function is not known, but it appears unlikely. PKC $\beta$ is expressed in most but not all tissues and we have preliminary evidence that an agent which selectively activates PKC $\delta$ also induces apoptosis in haemopoietic cells. ${ }^{67}$ It may still be the case that this cellular process can be affected by only a few PKC isoenzymes.

In conclusion, whilst we are still at an early stage in our understanding of the involvement of PKC isoenzymes in disease, there is evidence that they represent feasible targets for therapeutic modulation. Before this can occur, more information is required about the function of individual PKC isoenzymes and redundancy of $\mathrm{PKC}$ isoenzymes in cell regulation. ${ }^{90} \mathrm{~A}$ wider range of isoenzyme specific activators and inhibitors also needs to be developed. When each of these objectives are realised, it is possible that another option will be available for drug intervention protocols, suitable for the treatment of a wide range of diseases.

Studies in this laboratory are supported by the BBSRC (JP) and the Leukaemia Research Fund. JML is a Royal Society University Research Fellow.

1 Levitzki A. Signal-transduction therapy. A novel approach to disease management. Eur f Biochem 1994;226:1-13.

2 Sandler RS, Lyles CM, Peipins LA, McAuliffe CA, Woosley JT, Kupper LL. Diet and risk of colorectal adenomas: macronutrients, cholesterol and fibre. $\mathcal{F}$ Natl Cancer Inst macronutrients, cho

3 Inoue $M$, Kishimoto A, Takai $Y$, Nishizuka $Y$. Studies on a cyclic nucleotide-independent protein kinase and its proenzyme in mammalian tissue. II. Proenzyme and its activation by calcium-dependent proteases from rat brain f Biol Chem 1977;252:7610-16.

4 Berridge MJ. Inositol trisphosphate and diacylglycerol as second messengers. Biochem $\mathcal{f} 1984 ; 220: 345-60$

5 Castagna M, Takai Y, Kaibuchi K, Sano K, Kikkawa U, Nishizuka Y. Direct activation of calcium-activated, phospholipid-dependent protein kinase by tumour-promotin phorbol esters. I Biol Chem 1982;257:7847-51.

6 Freed E, Gailit J, Van der Geer P, Ruoslahti E, Hunter T. A novel integrin $\beta$ subunit is associated with the vitronectin A novel integrin and is a substrate for protein kinase C. $E M B O \exists 1989 ; 8$ : and is a 955 -65.

7 Bankey P, Carlson A, Ortiz M, Singh R, Cerra F. Tumor necrosis factor production by Kupffer cells requires protein necrosis factor production by Kupffer cells require

8 Lord JM, Ashcroft SJH. Identification and characterization of $\mathrm{Ca}^{2+}$-phospholipid-dependent protein kinase in rat isof $\mathrm{Ca}^{2+}$-phospholipid-dependent protein kinase in rat

9 Lord JM, Johnson GD, Owen PJ. PKC- $\delta$ associates with vimentin in differentiated HL-60 cells. $\exists$ Cell Biochem 1994;18:86. 
10 Disatnik MH, Buraggi G, Mochly-Rosen D. Localization of protein kinase $\mathrm{C}$ isoenzymes in cardiac myocytes. Exp Cell Res 1994;210:287-97.

11 Berry N, Nishizuka Y. Protein kinase $C$ and $T$ cell activation. Eur f Biochem 1990;189:205-14.

12 Karin M. Signal transduction from cell surface to nucleus in development and disease. FASEB ₹ 1992;6:2581-90.

13 Clemens MJ, Trayner I, Menaya J. The role of protein kinase $C$ isoenzymes in the regulation of cell proliferation and differentiation. $\mathcal{F}$ Cell Sci 1992;103:881-7.

14 Lotem J, Sachs L. Hematopoietic cytokines inhibit apoptosis induced by transforming growth factor $\beta 1$ and cance chemotherapy compounds in myeloid leukemic cells. Blood 1992;80:1750-7.

15 Pongracz J, Johnson GD, Crocker J, Burnett D, Lord JM The role of protein kinase $C$ in myeloid cell apoptosis. Biochem Soc Trans 1994;22:593-7.

16 Kikkawa U, Ogita K, Shearman MS, Ase K, Sekiguchi K, Naor Z, et al. The family of protein kinase C: Its molecular heterogeneity and differential expression. Symposia on quaterogeneity and differential expression. Symposia on quantitative biology. Cold Spring Harbor:

17 Parker PJ, Kour G, Marais RM, Mitchell F, Pears C Schaap D, et al. Protein kinase C-a family affair. $\mathrm{Mol}$ Cell Endocrinol 1989;65:1-11.

18 Dekker LV, Parker PJ. Protein kinase C-a question of specificity. Trends Biochem Sci 1994;19:73-7.

19 Nishizuka Y. Intracellular signalling by hydrolysis of phospholipids and activation of protein kinase C. Science 1992 258:607-14.

20 Hug $\mathrm{H}$, Sarre TF. Protein kinase $\mathrm{C}$ isoenzymes: divergence in signal transduction? Biochem $\mathcal{F}$ 1993;291:329-43.

21 Nakanishi H, Brewer KA, Exton JH. Activation of zeta isoenzyme of protein kinase $C$ by phosphatidylinositol 3 isoenzyme of protein kinase $C$ by phosphatidylin

22 Singh SS, Chauhan A, Brockerhoff $\mathrm{H}$, Chauhan VPS. Activation of protein kinase $C$ by phosphatidylinositol 3,4 5-trisphosphate. Biochem Biophys Res Commun 1993;195 104-12.

23 Gschwendt M, Kielbassa K, Kittstein W, Marks F. PKC substrates: differential phosphorylation by PKC isoenzymes [abstract]. $\mathcal{f}$ Cell Biochem 1994;18:83D.

24 Asaoka Y, Nakamura S, Yoshida K, Nishizuka Y. Protein kinase C, calcium and phospholipid degradation. Trends Biochem Sci 1992;17:414-17.

25 Kochs G, Hummel R, Fiebich B, Sarre TF, Marme D, Hug $H$. Activation of purified human protein kinase $C$ alpha and beta 1 isoenzymes in vitro by $\mathrm{Ca}^{2+}$, phospatidylinosito and phosphatidylinositol 4,5-bisphosphate. Biochem $\mathcal{f}$ 1993;291:627-33.

26 Murti KG, Kaur K, Goorha RM. Protein kinase C associates with intermediate filaments and stress fibers. Exp Cell Res 1992;202:36-44.

27 Nishizuka Y. The role of protein kinase $C$ in cell surface signal transduction and tumour promotion. Nature 1984 308:693-8.

28 Weinstein IB. The role of protein kinase $\mathrm{C}$ in growth control and the concept of carcinogenesis as a progressive disorder in signal transduction. In: Nishizuka $\mathrm{Y}$, et al, eds. The biology and medicine of signal transduction. New York: Raven Press, 1990:307-16.

29 Garattini S. Pharmacology of second messengers: A critical appraisal. Drug Metabol Rev 1992;24:185-94

30 Pongracz J, Clark P, Neoptolemos JP, Lord JM. Expression of protein kinase $\mathrm{C}$ isoenzymes in colorectal cancer tissue and their differential activation by different bile acids. In $\mathfrak{f}$ Cancer 1995; in press.

31 Levy MF, Pocsidio J, Guillem JG, Forde K, LoGerfo P, Weinstein B. Decreased levels of protein kinase $C$ enzyme activity and protein kinase $C$ mRNA in primary colon activity and protein kinase C mRNA in prin
tumors. Dis Colon Rectum 1993;36:913-21.

32 Craven PA, Pfanstiel J, DeRubertis FR. Role of activation of protein kinase $\mathrm{C}$ in the stimulation of the colonic epithelial proliferation and reactive oxygen formation by bile acids. ₹ Clin Invest 1987;79:532-41.

33 O'Brian CA, Vogel VG, Singletary SE, Ward NE, Elevated protein kinase $\mathrm{C}$ expression in human breast tumo biopsies relative to normal breast tissue. Cancer Res 1989 49:3215-17.

34 Hirai M, Gamou S, Kobayashi M, Shimizu N. Lung cancer cells often express high levels of protein kinase $\mathrm{C}$ activity. Ұpn ₹ Cancer Res 1989;80:204-8.

35 Brooks G, Wilson RE, Dooley TP, Goss MW, Hart IR Protein kinase $C$ down-regulation, and not transient acProtein kinase $C$ down-regulation, and not transient activation, correlates

36 Blobe GC, Sachs CW, Khan WA, Fabbro D, Stabel S, Wetsel WC, et al. Selective regulation of expression of protein kinase $C$ (PKC) isoenzymes in multidrug-resistan MCF-7 cells-functional significance of enhanced expression of PKC-alpha. F Biol Chem 1993;268:658-64.

37 Westmacott D, Bradshaw D, Kumar MKH, Lewis EJ, Murray EJ, Nixon JS, et al. Molecular basis of new approaches to the therapy of rheumatoid arthritis. Mol Aspects Med 1991;12:395-473.

38 Garland LG. Is there a biochemical lesion in intrinsic asthma? Agents Actions 1989;Suppl 28:135-45.

39 Meurs H, Kauffman HF, Koeter GH, Timmermans A, De Vries K. Regulation of the beta-receptor adenylate cyclase system in lymphocytes of allergic patients with asthma: system in lymphocytes of allergic patients with asthma: nonspecific refractoriness of adenylate cyclase. $\mathfrak{F}$ Allergy Clin Immunol 1987;80:326-39.

40 Kurihara H, Murayama Y, Warbington ML, Champagne CME, Vandyke TE. Calcium dependent protein kinase C activity of neutrophils in localized juvenile periodontitis. Infect Immun 1993;61:3137-42.

41 Nabel G, Baltimore D. An inducible transcription factor activates expression of human immunodeficiency virus in T cells. Nature 1987;326:711-13.

42 Kinter AL, Poli G, Maury W, Folks TM, Fauci AS. Direct and cytokine-mediated activation of protein kinase $C$ induces human immunodeficiency virus expression in chronically infected promonocytic cells. $\mathcal{F}$ Virol 1990;64: ically in

43 Boneh A, Bach $\mathrm{G}$. Inhibition of protein kinase $\mathrm{C}$ activity in mucolipidosis type 4-a model for a new pathogenetic mechanism in inborn-errors of metabolism. Biochem Biophys Acta 1993;1182:64-8.

44 Bertrand F, Hermelin B, Paul A, Garcia I, Capeau E, Cherqui E, et al. Further evidence for abnormal protein kinase $\mathrm{C}$ regulation of macromolecule secretion in fibroblasts from cystic fibrosis patients. Biosci Rep 1990;10: 562-72.

45 Clarke EA, Leach KL, Trojanowski JQ, Lee VM. Characterisation and differential distribution of the three major human protein kinase $C$ isozymes (PKC alpha, PKC beta and PKC gamma) of the central nervous system in normal and Alzheimer's disease brains. Lab Invest 1991;64:35-44.

46 Shimohama S, Narita M, Matsushima H, Kimura J, Kameyama $\mathbf{M}$, Hagiwara $M$, et al. Assessment of protein kinase $\mathrm{C}$ isozymes by two-site immunoassay in human brains and changes in Alzheimer's disease. Neurology 1994; 43:1407-13.

47 Zhang W, Sakai N, Fu T, Okano Y, Hirayama H, Takenaka $\mathrm{K}$, et al. Diacylglycerol formation and DNA synthesis in endothelin-stimulated rate C6 glioma cells: The possible role of phosphatidylcholine breakdown. Neurosci Lett 1991; 123:164-6.

48 Battini F, Leggio A, Govoni S, Frattola L, Appolonio I, Ferrarese C, et al. Decrease in phorbol ester receptors in human brain tumors. Eur Neurol 1990;30:241-6.

49 Schmitz PG, Zhang K. Expression of protein kinase $C$ alpha (PKC alpha) in the remnant kidney-proposed role in potentiating glomerular capillary hypertension [abstract] f Am Soc Nephrol 1994;5:611.

$50 \mathrm{Gu}$ X, Bishop SP. Increased protein kinase $\mathrm{C}$ and isoenzyme redistribution in pressure-overload cardiac

51 Chumine RC Dun Res 1994;75:926-31. kinase $\mathrm{C}$ activity during cerebral ischaemia and after rekinase $C$ activity during cerebral ischaemia and after re52 Koizumi H, Kohno Y, Osada S, Ohno S, Ohkawara A Kuroki T. Differentiation-associated localization of $\mathrm{nPKC} \eta, \mathrm{Ca}^{2+}$-independent protein kinase $\mathrm{C}$ in normal human skin and skin diseases. $\mathcal{F}$ Invest Dermatol 1993;101 853-63.

53 Fisher GJ, Tavakkol A, Leach K, Burns D, Basta P, Loomis C, et al. Differential expression of protein kinase $C$ isoenzymes in normal psoriatic adult human skin-reduced expression of protein kinase $\mathrm{C}$ beta-II in psoriasis. 7 Invest Dermatol 1993;101:553-9.

54 Tang EY, Parker PJ, Beattie J, Housley MD. Diabetes induces selective alterations in the expression of protein kinase C isoforms in hepatocytes. FEBS Lett 1993;326: 117-23.

55 Inoguchi T, Battan R, Handler E, King GL. Persistent activation of protein kinase $\mathrm{C}$ isoform beta-II by diabetes in heart and aorta, and its differential reversibility by islet cell transplantation. Clin Res 1992;40:141.

56 Herbert JM. Protein kinase C: a key factor in the regulation of tumor cell adhesion to the endothelium. Biochem Pharmacol 1993;45:527-37.

57 Fisher DE. Apoptosis in cancer therapy: crossing the threshold. Cell 1994;78:539-42.

58 Trittton TR, Hickman JA. How to kill cancer cells: Membranes and cell signalling as targets in cancer chemotherapy. Cancer Cells 1990;2:95-105.

59 Gescher A. Towards selective pharmacological modulation of protein kinase $\mathrm{C}$ - opportunities for the developmen of novel antineoplastic agents. Br F Cancer 1992;66:10-19.

60 Horn F, Marks F, Fisher FJ, Marcelo CL, Voorhees JJ. Decreased protein kinase $\mathrm{C}$ activity in psoriatic versus normal epidermis. F Invest Dermatol 1987;88:220-2.

61 Chakravarty R, Rong X, Rice RH. Phorbol ester-stimulated phosphorylation of keratinocyte transglutaminase in the membrane anchorage region. Biochem $\mathcal{f} 1990 ; 271: 25-30$.

62 Takahashi M. Tezuka T, Towatari T, Katunuma N. Identification of hematoxylin-stainable protein in epidermal keratohyalin granules as phosphorylated cystatin alpha by protein kinase C. FEBS Lett 1991;287:178-80.

63 Bradshaw D, Hill CH, Nixon JS, Wilkinson SE. Therapeutic potential of protein kinase C inhibitors. Agents Actions 1993;38: 135-47.

64 Cirone M, Angeloni A, Barile G, Zompetta C, Venanzoni $M$, Torrisi MR, et al. Epstein-Barr virus internalization
and infectivity are blocked by selective protein kinase C inhibitors. Int $\mathcal{F}$ Cancer 1990;45:490-3.

65 Constantinescu SN, Cernescu CD, Popescu LM. Effects of protein kinase $C$ inhibitors on viral entry and infectivity. FEBS Lett 1991;292:31-3.

66 Ryves WJ, Evans AT, Oliver AR, Parker PJ, Evans FJ. Activation of the PKC isotypes $\alpha, \beta 1, \gamma, \delta$ and $\varepsilon$ by phorbol esters of different biological activities. FEBS Lett 1991; 288:5-9.

67 Lord JM, Garrone B, Griffiths G, Watters D. Apoptosis induced by Bistratene A in HL60 cells involves the selective activation of PKC- $\delta$ and its association with nuclear lamins and DNA replication sites. $\mathcal{F}$ Cell Biochem 1995; in press. 
68 Stanwell C, Gescher A, Watters D. Cytostatic and cytotoxic properties of the marine product Bistratene $A$ and analysi of the role of PKC in its mode of action. Biochem Pharmacol 1993;45:1753-61.

69 Roivainen R, Messing RO. The phorbol derivatives thymeleatoxin and 12-deoxyphorbol-13-O-phenylacetate-20 acetate cause translocation and down-regulation of multiple protein kinase C isozymes. FEBS Let 1993;319: tiple prot.

70 Wilkinson SE, Parker PJ, Nixon JS. Isoenzyme specificity of bisindolylmaleimides, selective inhibition of protein kinase C. Biochem ₹ 1993;294:335-7.

71 Cho YH, Ziboh VA: 13-hydroxyoctadecadienoic acid reverses epidermal hyperproliferation via selective inhibition of protein kinase C beta activity. Biochem Biophys Res Commun 1994;201:257-65.

72 Fearon ER, Vogelstein B. A genetic model of colorecta tumorigenesis. Cell 1990;61:759-67.

73 Lane DP. Cancer. p53, guardian of the genome. Nature 1994;358:15-16.

74 Vandenbark GR, Kuhn LJ, Niedel JE. Possible mechanism of phorbol diester-induced maturation of human proof phorbol diester-induced maturation of human pro-
myelocytic leukemia cells. $¥$ Clin Invest 1984;73:448-57.

myelocytic leukemia cells. f Clin Invest 1984;73:448-57.
75 Yamauchi Y, Nagasawa K, Mayumi T, Horiuchi T, Niho $\mathrm{Y}$. Activation of protein kinase $\mathrm{C}$ induces differentiation in the human T-lymphoblastic cell line MOLT-3. $\mathrm{Br} \mathscr{f}$ Cancer 1989;60:15-19.

76 Rozengurt E. Early signals in the mitogenic response. Science 1986;234:161-6.

77 Berry N, Nishizuka Y. Protein kinase C and T-cell activation Eur F Biochem 1990;189:205-14.

78 Sanchez V, Lucas M, Sanz A, Goberna R. Decreased protein kinase $C$ activity is associated with programmed cell death (apoptosis) in freshly isolated rat hepatocytes. Biosci Rep 1992;12:199-206.

79 Moore NC, Jenkinson EJ, Owen JJT. Effects of the thymic microenvironment on the response of thymocytes to stimulation. Eur $\mathcal{F}$ Immunol 1992;22:2533-7.

80 Komada Y, Zhang XL, Zhou YW, Tanaka S, Higashiyama $M$, Ido $M$, et al. Apoptotic cell death induced by antiIgM antibody and phorbol esters is inhibited by IL 4 in human B lymphoma cell line MBC-1. Cell Immunol 1994; 159:280-93.

81 Kiley S, Schaap D, Parker P, Hsieh L, Jaken S. Protein kinase $\mathrm{C}$ heterogeneity in $\mathrm{GH}_{4} \mathrm{C}_{1}$ rat pituitary cells. $\mathcal{F}$ Biol Chem 1990;265:15704-12.

82 Mischak H, Pierce JH, Goodnight J, Kazanietz MG, Blumberg PM, Muschinski JF. Phorbol ester-induced myeloid differentiation is mediated by protein kinase C-alpha and delta and not by beta 11 , epsilon, zeta and eta. $\mathcal{F}$ Biol Chem 1993;268:20110-15.

83 Murray NR, Baumgardner GP, Burns DJ, Fields AP. Protein kinase $C$ isotypes in human erythroleukemia (K562) cell proliferation and differentiation. Evidence that beta 11 protein kinase $C$ is required for proliferation. $f$ Biol Chem 1993;268:15847-53.

84 Goss VL, Hocevar BA, Thompson LJ, Stratton CA, Burns DJ, Fields AP. Identification of Nuclear $\beta I I$ protein kinase $C$ as a mitotic lamin kinase. $\mathcal{F}$ Biol Chem 1994;269:19074-80.

85 Evan GI, Wyllie AH, Gilbert CS, Littlewood TD, Land H, Brooks $\mathrm{M}$, et al. Induction of apoptosis in fibroblasts by c-myc protein. Cell 1992;89:119-28.

86 MacFarlane DE, Manzel L. Activation of $\beta$-isozyme of protein kinase $C(P K C \beta)$ is necessary and sufficient for protein kinase $C$ (PKC $\beta$ ) is necessary and sufficient for phorbol ester-induced differentiation of

87 Knox KA, Johnson GD, Gordon J. A study of protein kinase $\mathrm{C}$ isoenzyme distribution in relation to $\mathrm{Bcl}-2$ expression during apoptosis of epithelial cells in vivo. Exp Cell Res 1993;207:68-73.

88 Lazebnik YA, Cole S, Cooke CA, Nelson WG, Earnshaw WC. Nuclear events of apoptosis in vitro in cell-free mitotic extracts: a model system for analysis of the active phase of apoptosis. $\mathcal{F}$ Cell Biol 1993;123:7-22.

89 Pongracz J, Deacon EM, Lord JM. Activation versus apoptosis in neutrophils-differential involvement of PKC isoenzymes. $\mathcal{F}$ Cell Biochem 1995; in press.

90 Decock JBJ, Gillespie-Brown J, Parker PJ, Sugden PH

Fuller SJ. Classical, novel and atypical isoforms of PKC stimulate ANF and TRE/AP-1-regulated-promoter activity in ventricular cardiomyocytes. FEBS Lett 1994;356: 275-8. 